AperTO - Archivio Istituzionale Open Access dell'Università di Torino

A Test of the Potentialities of the APEX Software (Aqueous Photochemistry of Environmentallyoccurring Xenobiotics). Modelling the Photochemical Persistence of the Herbicide Cycloxydim in Surface Waters, Based on Literature Kinetics Data.

This is the author's manuscript

Original Citation:

Availability:

This version is available http://hdl.handle.net/2318/155199

since 2016-10-10T11:03:02Z

Published version:

DOI:10.1016/j.chemosphere.2013.10.078

Terms of use:

Open Access

Anyone can freely access the full text of works made available as "Open Access". Works made available under a Creative Commons license can be used according to the terms and conditions of said license. Use of all other works requires consent of the right holder (author or publisher) if not exempted from copyright protection by the applicable law. 


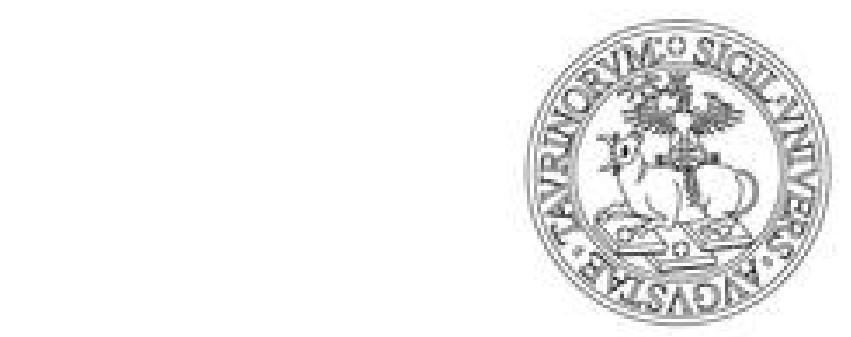

\section{UNIVERSITÀ DEGLI STUDI DI TORINO}

This Accepted Author Manuscript (AAM) is copyrighted and published by Elsevier. It is posted here by agreement between Elsevier and the University of Turin. Changes resulting from the publishing process - such as editing, corrections, structural formatting, and other quality control mechanisms - may not be reflected in this version of the text. The definitive version of the text was subsequently published in CHEMOSPHERE, 99, 2014, http://dx.doi.org/10.1016/j.chemosphere.2013.10.078.

You may download, copy and otherwise use the AAM for non-commercial purposes provided that your license is limited by the following restrictions:

(1) You may use this AAM for non-commercial purposes only under the terms of the CC-BY-NC-ND license.

(2) The integrity of the work and identification of the author, copyright owner, and publisher must be preserved in any copy.

(3) You must attribute this AAM in the following format: Creative Commons BY-NC-ND license (http://creativecommons.org/licenses/by-nc-nd/4.0/deed.en), http://dx.doi.org/10.1016/j.chemosphere.2013.10.078 


\title{
A test of the potentialities of the APEX software (Aqueous Photochemistry of Environmentally occurring Xenobiotics). Modelling the photochemical persistence of the herbicide cycloxydim in surface waters, based on literature kinetic data.
}

\section{Davide Vione}

Università di Torino, Dipartimento di Chimica, Via Pietro Giuria 5, 10125 Torino, Italy. Tel. +39011-6705296.Fax+39-011-6705242.E-mail: davide.vione@unito.it

\begin{abstract}
Based on literature kinetic data, it is shown that the photochemical transformation of cycloxydim (CXD) in surface waters would mainly occur by direct photolysis. Reaction of CXD with ${ }^{1} \mathrm{O}_{2}$ and with the triplet states of chromophoric dissolved organic matter would only account for a small fraction $(\leq 2 \%)$ of total phototransformation. The second-order reaction rate constant between CXD and ${ }^{\circ} \mathrm{OH}$ is not known. However, estimates based on data analysis with the APEX software and on diffusion-control kinetics in water indicate that ${ }^{\circ} \mathrm{OH}$ would account for less than $10 \%$ of CXD phototransformation. The photochemical half-life time of CXD in mid-latitude summertime would vary in the day-month range, depending on water chemistry and depth. Transformation would be favoured in shallow waters with low dissolved organic carbon.
\end{abstract}

Keywords: pesticides; surface-water photochemistry; direct and sensitised transformation; sunlight attenuation in water.

\section{Introduction}

Cycloxydim (2-[1-(ethoxyimino)butyl]-3-hydroxy-5-(tetrahydro-2H-thiopyran-3-yl)-2-cyclohexen1-one, hereafter CXD) is a cyclohexanedione oxime herbicide. It is used against a variety of weeds (EFSA, 2010) and it can reach the tens $\mathrm{ng} \mathrm{L}^{-1}$ level in groundwater (Silva et al., 2006).

Similarly to other cyclohexanedione oxime herbicides (Falb et al., 1990; Sevilla-Morán et al., 2008 and 2010a,b; Sandìn-Españaet al., 2013), CXD can undergo both direct and indirect photolysis under sunlight. Monadjemi et al. (2012) have determined the CXD reaction rate constants with ${ }^{1} \mathrm{O}_{2}$ $\left((1.0 \pm 0.2) \cdot 10^{7} \mathrm{M}^{-1} \mathrm{~s}^{-1}\right)$ and with the triplet state of phenalenone $\left((9.6 \pm 1.0) \cdot 10^{6} \mathrm{M}^{-1} \mathrm{~s}^{-1}\right)$. Coherently with previous works (Canonica et al., 2006 and 2008), the latter rate constant can be taken as representative of the reactivity between $\mathrm{CXD}$ and the triplet states of chromophoric dissolved organic matter $\left({ }^{3} \mathrm{CDOM} *\right)$. Moreover, the quantum yield of $\mathrm{CXD}$ direct photolysis has been recently determined as $(1.7 \pm 0.3) \cdot 10^{-2}$ in aqueous solution (Monadjemi et al., in press). These data allow the modelling of the transformation kinetics of CXD upon direct photolysis and reaction with ${ }^{1} \mathrm{O}_{2}$ and ${ }^{3} \mathrm{CDOM}^{*}$, by use of an approach that was recently developed and validated (Maddigapu et 
al., 2011; Vione et al., 2011; DeLaurentiis et al., 2012). In analogy with the vast majority of organic compounds (Buxton et al., 1988), CXD should react with ${ }^{\circ} \mathrm{OH}$ but the reaction rate constant is, unfortunately, not known.

In this short communication the expected photochemical persistence of CXD in surface waters is assessed and the possible importance of the unknown ${ }^{\circ} \mathrm{OH}$ pathway is discussed, exploiting the model ability to address photochemical pathways with unknown kinetics. In addition to providing important data about CXD environmental persistence (still poorly known at the moment), this work gives insight into the potential of the model: $(i)$ to assess the photochemical persistence of compounds, for which photoreactivity data are reported in the literature, and (ii) to fill up knowledge gaps by advanced data analysis, when some of the needed data are not available (e.g. the reaction rate constant with $\left.{ }^{\bullet} \mathrm{OH}\right)$.

\section{The APEX software}

APEX (Aqueous Photochemistry of Environmentally-occurring Xenobiotics) is a software application that has been derived from the photochemical model described above. APEX is available for free download at http://chimica.campusnet.unito.it/do/didattica.pl/Quest?corso=7a3d (click on the current year; the downloaded files include the User's Guide that contains a comprehensive account of the model equations). APEX is based on the free software Octave (http://sourceforge.net/projects/octave/files/Octave\%20Windows\%20binaries/). In this work the Plotgraph function of APEX was extensively used, which generates 3D plots of several quantities (for a total of 36 output options), including half-life times and transformation rate constants of pollutants. They can be plotted as a function of water chemistry and depth parameters (or of photolysis quantum yields and second-order reaction rate constants, if unknown). To account for the day-night cycle in outdoor conditions, the time unit of APEX is a standard summer sunny day (SSD), which corresponds to fair-weather 15 July at mid latitude. Within APEX, radiation absorption by mixtures of absorbers is calculated at each wavelength by a Lambert-Beer approach. To assess the second-order reaction rate constant with ${ }^{\circ} \mathrm{OH}$ that would produce the same CXD degradation kinetics as the direct photolysis, the original code was modified as reported in the Supplementary Material (hereafter SM). In this way, it was possible to have the Plotgraph function plot the required second-order ${ }^{\circ} \mathrm{OH}$ rate constant as a function of water chemistry and depth. A further issue is the fact that sunlight does not penetrate vertically into surface waters, although refraction at the air-water interface deviates the light path towards the vertical. This issue can be taken into account by the relationship $d=l \sqrt{1-\left(n^{-1} \sin z\right)^{2}}$, where $d$ is the depth of the water column, $l$ the path length of sunlight in water, $n=1.34$ the refraction index of water, and $z$ the solar zenith angle. On 15 July at mid latitude, one has $d=0.93 l$ at the solar noon and $d=0.83 l$ at $\pm 3 \mathrm{~h}$ from noon, which is a reasonable daily average. Further information is reported in the User's Guide of APEX. The results of APEX apply to well-mixed waters, such as the epilimnion of deep lakes. For this reason, photochemical modelling was not extended to column depth values above $10 \mathrm{~m}$. 


\section{Results and Discussion}

The modelling of CXD photochemical transformation in surface waters was based on the reported values of the second-order reaction rate constants with ${ }^{1} \mathrm{O}_{2}$ and ${ }^{3} \mathrm{CDOM}^{*}\left((1.0 \pm 0.2) \cdot 10^{7} \mathrm{M}^{-1} \mathrm{~s}^{-1}\right.$ and $(9.6 \pm 1.0) \cdot 10^{6} \mathrm{M}^{-1} \mathrm{~s}^{-1}$, respectively), on the direct photolysis quantum yield $\left((1.7 \pm 0.3) \cdot 10^{-2}\right)$ and on the reported absorption spectrum of CXD in water (Monadjemi et al., 2012; Monadjemi et al., in press). Therefore, the calculated phototransformation kinetics is the sum of direct photolysis and reaction with ${ }^{1} \mathrm{O}_{2}$ and ${ }^{3} \mathrm{CDOM}^{*}$. Figure 1a shows the half-life time of $\mathrm{CXD}\left(t_{1 / 2}=\ln 2 k^{-1}\right.$, units of $\mathrm{SSD}$, where $k$ is the overall first-order transformation rate constant of CXD), as a function of DOC (dissolved organic carbon, which measures DOM, dissolved organic matter) and of the path length $l$ of sunlight in water (remember that the water column depth is $d=l \sqrt{1-\left(n^{-1} \sin z\right)^{2}} \approx 0.83 l$ ). Other water parameters (nitrate, nitrite, carbonate and bicarbonate) are relevant to ${ }^{\circ} \mathrm{OH}$ and, therefore, they are not discussed at this stage.

From Figure 1a and its source data (which can be obtained as a csv file with the Savetable function of APEX) one gets that $t_{1 / 2}$ varies from less than one day (for $l<0.5 \mathrm{~m}$ and DOC $<1 \mathrm{mg} \mathrm{C}$ $\mathrm{L}^{-1}$ ) to 1-2 months. Note that laboratory data gave estimates for the CXD half-life time upon direct photolysis (one day or less; EFSA, 2010), which only agree with the low- $l$ and low-DOC range of our model output. This is not surprising, because laboratory experiments (often carried out in ultrapure water) use very short water column depths and cannot reproduce the actual environmental conditions. On the one side the agreement provides evidence for the validity of the present model approach, which is based on reaction rate constants and photolysis quantum yields. On the other hand, conclusions based only on laboratory results could lead to a large overestimation of CXD phototransformation rates in surface waters, unless direct photolysis quantum yields and reaction rate constants are experimentally derived and combined with a model approach.

In Figure $1 \mathrm{a}$, the increase of $t_{1 / 2}$ with increasing $l$ (and $d$ as a consequence) is due to the fact that photochemical processes are most effective in shallow water bodies. Indeed, the bottom layers of a deep water body are poorly illuminated by sunlight. The $t_{1 / 2}$ increase with increasing DOC is due to the inhibition of direct photolysis, which is by far the main CXD phototransformation pathway (vide infra). In fact, high DOC also means high CDOM, which absorbs sunlight and competes with CXD for irradiance, slowing down the direct photolysis. High CDOM enhances degradation by ${ }^{1} \mathrm{O}_{2}$ and ${ }^{3} \mathrm{CDOM}^{*}$ (reactions 1,2 , where ISC $=$ inter-system crossing; Monadjemi et al., 2012), but these processes do not offset the photolysis inhibition.

$$
\begin{aligned}
& \mathrm{CDOM}+\mathrm{hv} \rightarrow{ }^{1} \mathrm{CDOM}^{*} \stackrel{I S C}{\longrightarrow}{ }^{3} \mathrm{CDOM}^{*} \\
& { }^{3} \mathrm{CDOM}^{*}+\mathrm{O}_{2} \rightarrow \mathrm{CDOM}+{ }^{1} \mathrm{O}_{2}
\end{aligned}
$$

Figure $1 \mathrm{~b}$ reports the fraction of CXD transformation that is accounted for by direct photolysis, again as a function of $l$ and DOC. It is shown that photolysis would be by far the main 
photoinduced transformation process of CXD in surface waters. Indeed, the $\leq 2 \%$ fraction of transformation that is accounted for by ${ }^{1} \mathrm{O}_{2}$ and ${ }^{3} \mathrm{CDOM}^{*}$ is much lower than the uncertainty associated with the model (vide infra). Whatever marginal, the relative importance of ${ }^{1} \mathrm{O}_{2}$ would be approximately double compared to ${ }^{3} \mathrm{CDOM}^{*}$. The (small) decrease of the direct photolysis fraction with increasing DOC is due to the increased importance of CXD degradation by ${ }^{1} \mathrm{O}_{2}$ and ${ }^{3} \mathrm{CDOM}^{*}$. The latter processes are triggered by irradiation of CDOM (reactions 1,2), which absorbs visible radiation in addition to $\mathrm{UV}$. In contrast, CXD only absorbs in the $\mathrm{UV}$. Because visible light penetrates more deeply than UV in the water column, the relative importance of ${ }^{1} \mathrm{O}_{2}$ and ${ }^{3} \mathrm{CDOM} *$ increases and that of direct photolysis decreases with increasing $d$ or $l$.

The results reported in Figure 1 are valid for summertime conditions (15 July at mid latitude), but the half-life times of CXD would be higher in different seasons than summer. Figure 2 reports $t_{1 / 2}$ at mid latitude, as a function of the month of the year (calculated with the APEX_season function) together with the associated errors ( $\pm \sigma$, assessed with the APEX_errors function), for $l=5$ $\mathrm{m}$ and DOC $=5 \mathrm{mg} \mathrm{C} \mathrm{L}^{-1}$. In the summer season $t_{1 / 2}$ is around 11 days, but in December it is for instance 26 times higher than in June. Error bounds are around $\pm 20 \%$ of the $t_{1 / 2}$ value. Note that under the considered water chemistry conditions, reported in the caption to Figure 2, the summertime $t_{1 / 2}$ for CXD is considerably higher than the estimates based on laboratory data (EFSA, 2010). The difference between laboratory-based estimates and the APEX output is valid a fortiori for the winter season.

The modified APEX code allowed the assessment of the second-order reaction rate constant between $\mathrm{CXD}$ and ${ }^{\circ} \mathrm{OH}\left(k_{C X D}{ }^{\circ} \mathrm{OH}\right)$, which would be required for the reaction with ${ }^{\circ} \mathrm{OH}$ to be as important as the direct photolysis in CXD transformation (see Figure SM1 in SM). The required value of $k_{C X D ; O H}$, as a function of either $l$ and DOC or of nitrate and bicarbonate, is about one order of magnitude higher than the diffusive control limit in aqueous solution (Buxton et al., 1988). This means that ${ }^{\circ} \mathrm{OH}$ degradation cannot play a comparable role as the direct photolysis, and that the relative importance of ${ }^{\circ} \mathrm{OH}$ in $\mathrm{CXD}$ phototransformation would not be higher than $10 \%$.

\section{Conclusions}

The photochemical transformation of CXD in surface waters would mainly take place by direct photolysis. The relative importance of ${ }^{1} \mathrm{O}_{2}$ and ${ }^{3} \mathrm{CDOM}^{*}$ in $\mathrm{CXD}$ photodegradation (a few percent of the total transformation) is considerably lower than the uncertainty of the model estimates. The reaction with ${ }^{\circ} \mathrm{OH}$ would at most account for $\sim 10 \%$ of CXD transformation, if the relevant secondorder reaction rate constant is near the diffusion-control limit for aqueous solutions.

In mid-latitude summertime, the photochemical half-life time of CXD would vary from less than one day to 1-2 months, depending on water chemistry and depth. Phototransformation would be enhanced in shallow and DOM-poor waters and inhibited under the opposite conditions. Furthermore, the kinetics of mid-latitude photochemical transformation in December would be about 26 times slower than in June. These results indicate that assessments based only on laboratory 
irradiation experiments, which predict CXD photochemical lifetimes of less than one day, might lead to a large overestimation of CXD photodegradation rate constants in the environment.

\section{Acknowledgements}

Financial support by Università di Torino and Compagnia di San Paolo - EU Accelerating Grants, project TO_Call2_2012_0047 (Impact of radiation on the dynamics of dissolved organic matter in aquatic ecosystems - DOMNAMICS), is kindly appreciated.

\section{References}

Buxton, G.V., Greenstock, C.L., Helman, W.P., Ross, A.B., 1988. Critical review of rate constants for reactions of hydrated electrons, hydrogen atoms and hydroxyl radicals $\left({ }^{\bullet} \mathrm{OH} / \mathrm{O}^{-\bullet}\right)$ in aqueous solution. J. Phys. Chem. Ref. Data 17, 1027-1284.

Canonica, S., Hellrung, B., Mueller, P., Wirz, J., 2006. Aqueous oxidation of phenylurea herbicides by triplet aromatic ketones. Environ. Sci. Technol. 40, 6636-6641.

Canonica, S., Laubscher, H.U., 2008. Inhibitory effect of dissolved organic matter on tripletinduced oxidation of aquatic contaminants. Photochem. Photobiol. Sci. 7, 547-551.

De Laurentiis, E., Chiron, S., Kouras-Hadef, S., Richard, C., Minella, M., Maurino, V., Minero, C., Vione, D., 2012. Photochemical fate of carbamazepine in surface freshwaters: Laboratory measures and modeling. Environ. Sci. Technol. 46, 8164-8173.

EFSA (European Food Safety Authority), 2010. Conclusion on the peer review of the pesticide risk assessment of the active substance cycloxydim. EFSA Journal 8, 1669-1741.

Falb, L. N., Bridges, B. C., Smith, A. E., 1990. Effects of pH and adjuvants on clethodim photodegradation. J. Agric. Food Chem. 38, 875-878.

Maddigapu, P. R., Minella, M., Vione, D., Maurino, V., Minero, C., 2011. Modeling phototransformation reactions in surface water bodies: 2,4-Dichloro-6-nitrophenol as a case study. Environ. Sci. Technol. 45, 209-214.

Monadjemi, S., Ter Halle, A., Richard, C., 2012. Reactivity of cycloxydim toward singlet oxygen in solution and on wax film. Chemophere 89, 269-273.

Monadjemi, S., De Sainte-Claire, P., Abrunhosa-Thomas, I., Richard, C., in press. Photolysis of cycloxydim, a cyclohexanedione oxime herbicide. Detection, characterization and reactivity of the iminyl radical. Photochem. Photobiol. Sci. DOI: 10.1039/C3PP50209K.

Sandín-España, P., Sevilla-Morán, B., Calvo, L., Mateo-Miranda, M. M., Alonso-Prados, J. L., 2013. Photochemical behaviour of alloxydim herbicide in environmental waters.Structural elucidation and toxicity of degradation products. Microchem. J. 106, 212-219. 
Sevilla-Morán, B., Sandín-España, P., Vicente-Arana, M. J., Alonso-Prados, J. L., García-Baudín, J. M., 2008. Study of alloxydim photodegradation in the presence of natural substances: Elucidation of transformation products. J. Photochem. Photobiol. A: Chem. 198, 162-168.

Sevilla-Morán, B., Mateo-Miranda, M. M., Alonso-Prados, J. L., García-Baudín, J. M., SandínEspaña, P., 2010a. Sunlight transformation of sethoxydim-lithium in natural waters and effect of humic acids. Intern. J. Environ. Anal. Chem. 90, 487-496.

Sevilla-Morán, B., Alonso-Prados, J. L., García-Baudín, J. M., Sandín-España, P., 2010b. Indirect photodegradation of clethodim in aqueous media. By-product identification by quadrupole time-of-flight mass spectrometry. J. Agric. Food Chem. 58, 3068-3076.

Silva, E., Batista, S., Viana,P., Antunes, P., Serôdio, L., Cardoso, A. T., Cerejeira, M. J., 2006. Pesticides and nitrates in groundwater from oriziculture areas of the 'Baixo Sado' region (Portugal). Inter. J. Environ. Anal. Chem. 86, 955-972.

Vione, D., Maddigapu, P. R., De Laurentiis, E., Minella, M., Pazzi, M., Maurino, V., Minero, C., Kouras, S., Richard, C., 2011. Modelling the photochemical fate of ibuprofen in surface waters. Wat. Res. 45, 6725-6736. 

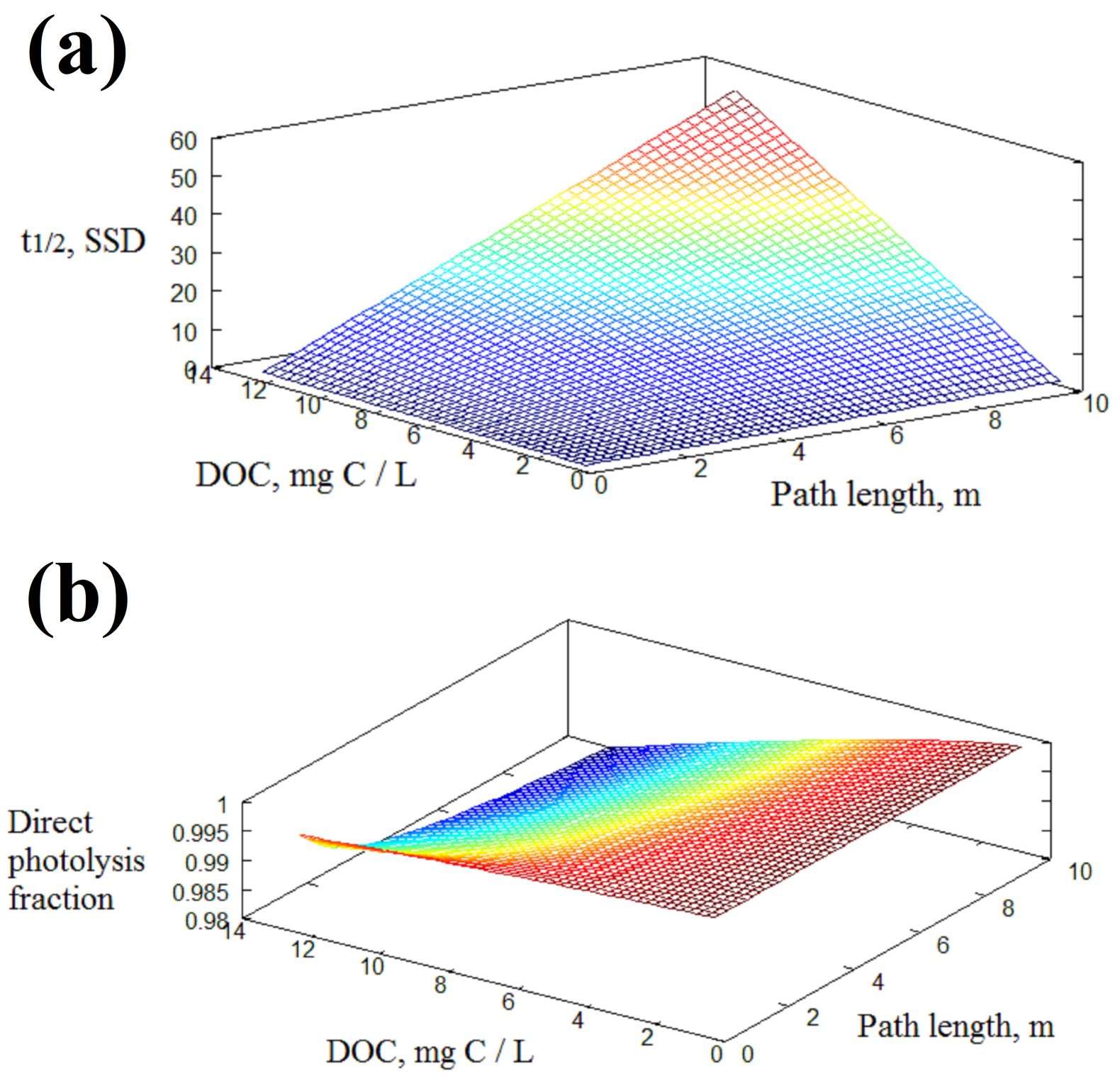

Figure 1. (a) Trend of the CXD photochemical half-life time (units of Summer Sunny Days, SSD) as a function of dissolved organic carbon (DOC) and the path length $l$ of sunlight in water. (b) Trend of the fraction of CXD degradation accounted for by direct photolysis, as a function of DOC and the path length $l$.

Note that the water depth is $d \approx 0.83 l$. Other (constant) water conditions are: $0.1 \mathrm{mM}$ nitrate, $1 \mu \mathrm{M}$ nitrite, $2 \mathrm{mM}$ bicarbonate, $10 \mu \mathrm{M}$ carbonate. 


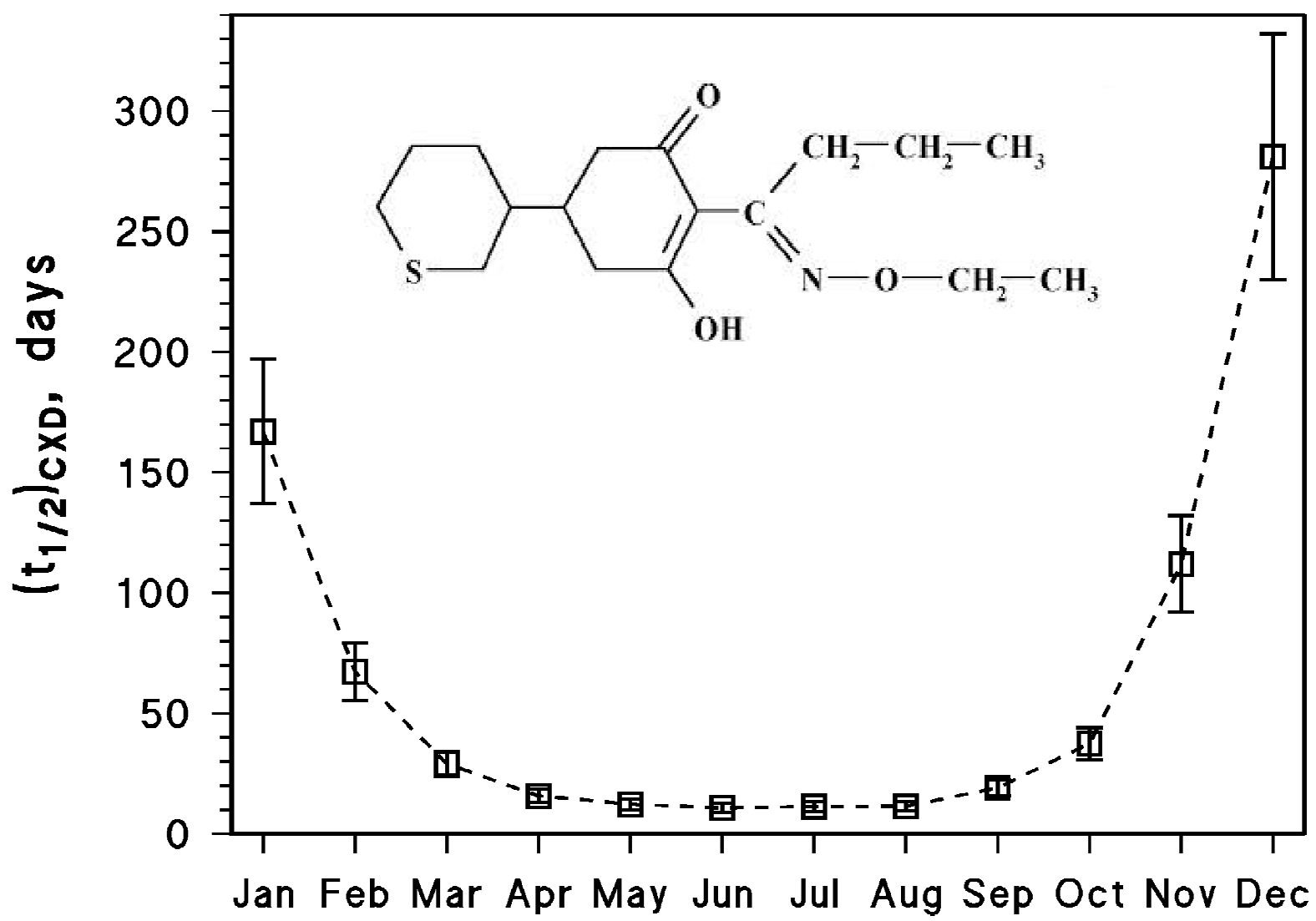

Figure 2. Trend of the CXD photochemical half-life time, as a function of the month of the year (mid-latitude conditions). Half-time units are days of the relevant month. Error bounds represent $\pm \sigma$. Water conditions: $5 \mathrm{~m}$ path length, $5 \mathrm{mg} \mathrm{C} \mathrm{L}{ }^{-1} \mathrm{DOC}, 0.1 \mathrm{mM}$ nitrate, $1 \mu \mathrm{M}$ nitrite, $2 \mathrm{mM}$ bicarbonate, $10 \mu \mathrm{M}$ carbonate. The structure of CXD is reported on the plot. 